\title{
Altered Phase Precession and Compression of Temporal Sequences by Place Cells in Epileptic Rats
}

\author{
Pierre-Pascal Lenck-Santini and Gregory L. Holmes \\ Neuroscience Center at Dartmouth, Dartmouth Medical School, Lebanon, New Hampshire 03756
}

In the hippocampus, pyramidal cells encode information in two major ways: rate coding and temporal coding. Rate coding, in which information is coded through firing frequency, is exemplarily illustrated by place cells, characterized by their location-specific firing. In addition, the precise temporal organization of firing of multiple place cells provides information, in a compressed time window, about the temporal sequence of the locations visited by the animal. This encoding is accomplished through phase precession, a phenomenon whereby unit firing is linked to theta rhythm, one of the major hippocampal EEG oscillations. Although it is likely that this type of processing is critical for normal brain function, its involvement in pathologies associated with cognitive disorders is unknown. In this experiment, we determined whether the temporal organization of place cell firing is affected in an animal model of mesial temporal lobe epilepsy (MTLE), a disease accompanied with cognitive impairment. We investigated hippocampal coding and its relationship to theta rhythm in rats after status epilepticus (SE), a condition that leads to MTLE. We found a great proportion of SE place cells had aberrant phase/precession pattern and temporal organization of firing among pairs of neurons, which constitutes the compression of temporal sequences, was altered in SE rats. The same animals were also markedly impaired in the water maze task, a measure of spatial memory. We propose that the synaptic and cellular alterations observed in MTLE induce aberrant temporal coding in the hippocampus, contributing in turn to cognitive dysfunction.

Key words: hippocampus; place cells; temporal lobe epilepsy; phase precession; temporal coding; oscillations

\section{Introduction}

Precise temporal organization of neuronal firing activity is believed to be a fundamental aspect of normal information processing. In addition to rate coding, in which information is conveyed through the firing frequency of single neurons, temporal coding is achieved through the temporal interaction of multiple neuronal firing.

In the hippocampus, pyramidal cells are characterized not only by their location-specific firing (O'Keefe and Dostrovsky, 1971; O'Keefe, 1976) but also by their temporal firing relationship with hippocampal theta oscillations $(6-12 \mathrm{~Hz})$. When the rat enters their firing field, place cells will fire preferentially on the peak of the CA1 recorded theta cycle (Fig. 1C). As the rat crosses the field, the cells fire earlier on successive theta peaks (Fig. 1C,D) (O’Keefe and Recce, 1993; Skaggs et al., 1996). This phenomenon is called phase precession. Because of this characteristic, two cells with partially overlapping fields will fire at a specific but different phase of the ongoing theta cycle. Their relative firing interval will be directly related to the distance separating their fields (Fig. 2) and preserved as the animal crosses the fields. As a result, the

Received Nov. 12, 2007; revised April 1, 2008; accepted April 2, 2008.

This work was supported in part by National Institute of Neurological Disorders and Stroke Grants NS41595 and NS44296 and the Epilepsy Foundation Research Grant Program. We thank gratefully Caroline Geisler, Gregory Quirk, and Eva Pastalkova for their suggestions on analyzing the data as well as their comments on previous versions of this manuscript.

Correspondence should be addressed to Pierre-Pascal Lenck-Santini, Neuroscience Center at Dartmouth, Dartmouth Medical School, One Medical Center Drive, Lebanon, NH 03756. E-mail: lenck@dartmouth.edu.

DOI:10.1523/JNEUROSCI.5024-07.2008

Copyright $\odot 2008$ Society for Neuroscience $\quad$ 0270-6474/08/285053-10\$15.00/0 sequence of events experienced by the animal and its timing (the rat crossed field A $x$ ms before field B) is encoded: the time difference between action potentials (APs) is observed on a large timescale (the time it takes to get from field to field) and also in the order of tens of milliseconds (the firing interval between cells within a theta cycle). The firing sequences of cell assemblies observed in the real time are compressed in a time window short enough to induce long-term potentiation (LTP)-like synaptic changes.

By definition, phase precession requires the cell oscillation frequency to be slightly faster than the general hippocampal oscillation. Whether this phenomenon is attributable to intrinsic cell properties, hippocampal network properties or a combination of both is still a matter of debate (Maurer and McNaughton, 2007). However, we surmise that damage to the hippocampal circuitry would alter phase precession. Here, we investigated the effect of temporal lobe epilepsy (MTLE), a pathological condition associated with aberrant synaptic reorganization and damage of hippocampal neurons, on temporal coding.

MTLE, the most common form of symptomatic epilepsy, is often associated with pronounced memory impairments (Hermann et al., 1997; Helmstaedter, 2002). Although it is thought that these deficits are attributed to damage and synaptic reorganization in the hippocampal formation (Holmes, 2005), little is known about the functional aspects of such alterations. We hypothesize that synaptic and cellular alterations observed in MTLE should lead to changes in phase precession. Such aberrant tem- 
A

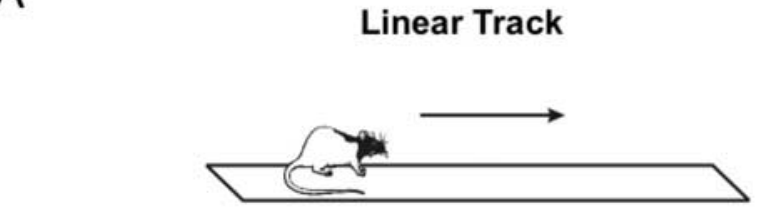

B Rate $(\mathbf{H z})$
$\square \begin{aligned} & 33.8 \\ & 23.6 \\ & 11.7 \\ & 4.6 \\ & 1.1 \\ & 0.0\end{aligned}$

C

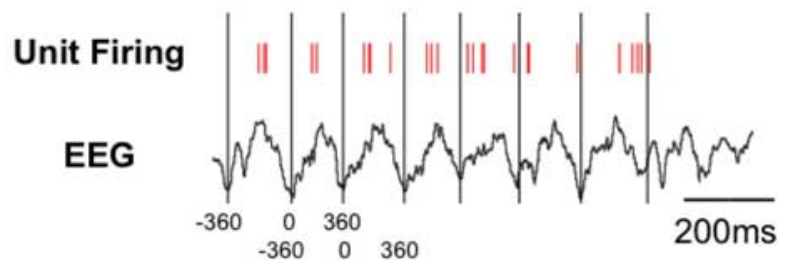

D

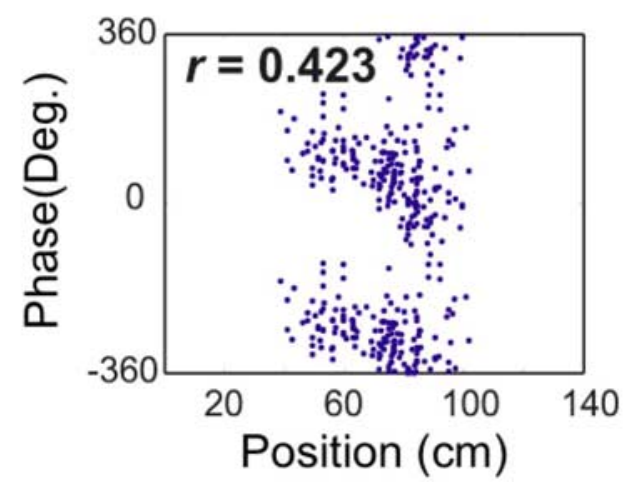

Figure 1. Phase precession of hippocampal place cells. $A$, Place cells were recorded in rats while they were running back and forth on a linear track. $B$, Top-view spatial firing map of a cell for the entire session. C, Hippocampal EEG and firing activity of the same cell (red bars) during a single firing field crossing. As the rat crosses the field, the cell bursting activity occurs at a slightly higher frequency than the theta EGG signal. On successive cycles, APs appear in advance (precess) to the peak of the theta wave. Long vertical bars represent the $0^{\circ}$ theta phase (i.e., the trough of the theta wave). $\boldsymbol{D}$, The theta phase of APs from the same cell is plotted against position, for multiple field crossings. Each AP is plotted twice, by a factor of $360^{\circ}$; $r$, linearcircular correlation coefficient.

poral coding could explain the frequent cognitive deficits observed in patients.

To approach this question, we investigated hippocampal coding and its relationship to theta rhythm in rats after status epilepticus (SE), a condition that leads to MTLE. Like humans, rats with MTLE, have impaired learning and memory in spatial tasks (Liu et al., 2003). We found that SE disrupted both phase precession and compression, along with deficits in spatial learning.

\section{Materials and Methods}

Long-Evans black-hooded rats (300-350 g) were used in the study. All behavioral, pharmacological, and surgical procedures were done in accordance with National Institutes of Health guidelines and approved by the Dartmouth College Institutional Care and Use Committee. Rats were divided into a control group (CTR) $(n=5)$ and an SE group $(n=6)$ and implanted with movable electrodes in the hippocampus. Rats were trained to run between the two ends of a linear track $(130 \times 14 \mathrm{~cm})$ (Fig. $1 \mathrm{~A}$ ) for a food reward (20 mg sucrose pellets).

Seizure induction. The SE group was given intraperitoneally lithium chloride $(3 \mathrm{mEq} / \mathrm{kg}) 18 \mathrm{~h}$ before an intraperitoneal injection of pilocarpine $(34 \mathrm{mg} / \mathrm{kg}$ ) on postnatal day 60 (P60). Thirty minutes before the pilocarpine injection, rats received a subcutaneous injection of the peripheral muscarinic cholinergic receptor antagonist, methylscopolamine $(1 \mathrm{mg} / \mathrm{kg})$ to prevent peripheral cholinergic effects. Seizures were stopped $3 \mathrm{~h}$ after induction by diazepam $(5 \mathrm{mg} / \mathrm{kg}$, i.p.). For the control group, normal saline was given intraperitoneally $18 \mathrm{~h}$ before an additional saline injection on P60.

Electrode array and implantation. The multielectrode array we used is manufactured in Robert U. Muller's Laboratory (State University of New York, Downstate Medical Center, Brooklyn, NY). The version used here had six independently drivable tetrodes and two $100 \mu \mathrm{m}$ single-wire electrodes aimed to make differential recordings above and below the CA1 pyramidal cell layer. The array was surgically implanted as described by Lenck-Santini et al. (2002). Rats were allowed a week recovery.

Data acquisition. Before recordings, each electrode in the implant was checked for waveforms of sufficient amplitude. This was done as the rat explored an open-field area for food pellets. At the beginning of the experiment, the electrodes were monitored twice a day and individually advanced $20 \mu \mathrm{m}$ until ripples and unit activity from CA1 started to appear. Then, the electrodes were advanced $10 \mu \mathrm{m}$ or less, once a day until one or more pyramidal cells with waveform amplitude $>150 \mu \mathrm{V}$ were isolated. Each cell or group of cells was recorded for a $12 \mathrm{~min}$ session on the linear track. Once the recording was performed, the electrodes were advanced $20 \mu \mathrm{m}$ and other units recorded. Care was taken not to record the same cell twice: if a place field and/or waveform looked similar to those observed on the preceding recording, the cell was discarded.

The signal from the electrodes was preamplified directly from the rat's head by operational amplifiers mounted as followers (gain $=1$ ). The signal was transmitted via a cable, through a rotating commutator (Neuralynx, Bozeman, MT). Electrophysiological and position data were acquired on a DigitaLynx (Neuralynx) recording system. Two red light emitting diodes ( $120^{\circ}$ view angle) were mounted $3 \mathrm{~cm}$ apart (one on each side of the head stage) to track the animal location even during unusual head movements. Position data were sampled at $30 \mathrm{~Hz}$ by a CCD camera and digitized by a frame grabber (DataTranslation, Marlboro, MA). Sessions with $>3 \%$ position detection errors were discarded. Single-unit recordings were filtered $(300-5000 \mathrm{~Hz})$, amplified (gain $=5-10 \mathrm{~K})$, and sampled at $32 \mathrm{kHz}$, whereas electroencephalogram (EEG) signals were recorded wideband $(0.1-5000 \mathrm{~Hz}$ ), amplified (gain $=100-1000)$, and digitized at $10 \mathrm{kHz}$.

Data analysis. Unit discrimination was done with cluster-cutting software (Cluster 3D; Neuralynx). Only cells with peak spike amplitude of at least $150 \mu \mathrm{V}$ on at least one tetrode wire were evaluated. To discriminate between pyramidal cells and interneurons, we used the same criteria as described by Lenck-Santini et al. (2002). All additional data analyses were performed using Matlab (Mathworks, Natick, MA).

Place cell spatial properties. Firing maps were first computed in two dimensions by methods introduced previously (Muller and Kubie, 1987; Lenck-Santini et al., 2002). This allowed us to determine the proportion of place cells in both CTR and SE rats. A pyramidal cell was considered a place cell if (1) it had at least one place field (more than nine contiguous pixels with firing greater than the session global firing rate) and (2) it had a spatial coherence $>0.3$. However, because place cells are directional in the linear track, most of our calculations were performed on one dimensional maps of a subset of centrally localized cells as follows: Firing data were analyzed into one dimension only (along the $x$ coordinates), and separated between journeys of each direction (left $\rightarrow$ right, right $\rightarrow$ left). For each trial, firing rate was calculated in bins of $100 \mathrm{~ms}$ duration. Position coordinates were recalculated so that 1 pixel $=1.75 \mathrm{~cm}$. After filtering out of episodes of running speed $\leq 5 \mathrm{~cm} / \mathrm{s}$ (estimated over periods of $200 \mathrm{~ms}$ ), one-dimensional rate maps were established by averaging all trial vectors.

A computer program separated trials into left-bound and right-bound journeys and determined the beginning and end of each trial on the basis of the position data ( $x$ coordinates only). Then, positional data were 
Large Overlap
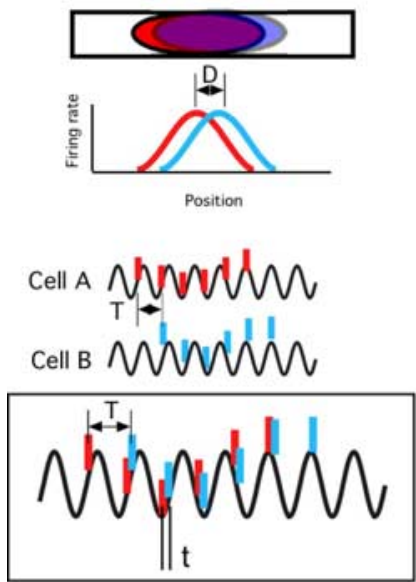

Cell $\mathrm{A}+$ Cell $\mathrm{B}$
Small Overlap
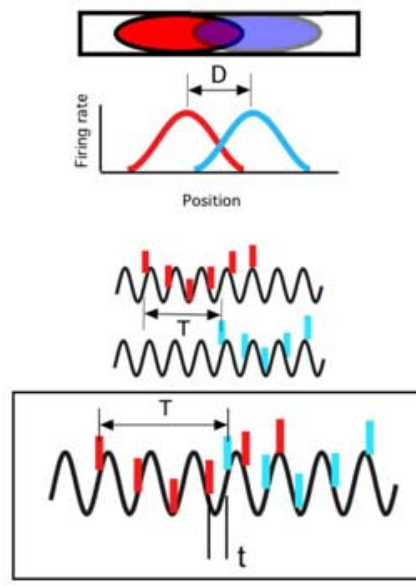

Cell $A+$ Cell B

Figure 2. Schematic representation of the compression of temporal sequences phenomenon. Place cells with partially overlapping place fields (red and blue) will show a different firing relationship depending on whether the field centers are distant (left) or close to each other (right). There is a linear relationship between the interfield distance $(D)$ and the time required to go from field center to another (running time, $T$ ). Because each cell firing is doing phase precession, there is also a relationship between the running time $(T)$ and the time interval between action potentials within the same theta cycle $(t)$. Cells with close fields will tend to fire at a short time interval, whereas cells with distant fields will fire at long time intervals. Black traces, EEG during the crossing of both place fields. Red and blue vertical lines, APs of each cell.

inspected on a trial-by-trial basis by the experimenter. Any trial with a corrupted position signal was discarded. In each direction, a cell was considered as a place cell if (1) it fired on average $>0.3 \mathrm{~Hz}$ during a journey type, (2) the information content for a journey was $>0.7$ bits/ spikes, and (3) there were more than four consecutive pixels in which the rate was greater or equal to a quarter of the session rate for the entire journey. Two-dimensional coherence and information content were calculated as described by Liu et al. (2003).

The directionality index was calculated as follows: $\mathrm{DI}=\left(L_{\text {mean }}-\right.$ $\left.R_{\text {mean }}\right) /\left(L_{\text {mean }}+R_{\text {mean }}\right)$, where $L_{\text {mean }}$ and $R_{\text {mean }}$ are the firing rate in the left or right direction, respectively.

One-dimensional information content was calculated for each direction as follows:

$$
1=\sum_{i}\left(\frac{\lambda(i)}{\lambda} \log _{2} \frac{\lambda(i)}{\lambda} p(i)\right)
$$

where $i$ is the location, $p(i)$ is the probability of being in pixel $(i), \lambda(i)$ is the rate in pixel (i), and $\lambda$ is the overall rate. $\lambda$ here is defined as $\Sigma(p(i) \times$ $\lambda(i))$.

Coherence was defined as the correlation between the rate in each pixel and the average rate of its neighbors. Peak rate of a field corresponded to the average of the rate in the highest firing pixel and its neighbors. The centroid of a field was defined as the center of mass of the field [i.e., the spatial center of the field as determined by the firing rate (Fenton et al., 2000)].

Phase precession analysis. Only place cells that had a field further than 10 pixels $(17.5 \mathrm{~cm})$ from the nearest end of the track were included in the phase precession analysis. The EEG signal was filtered after acquisition in the theta band $(5-12 \mathrm{~Hz})$ using a Butterworth filter. Theta phase was determined by the Hillbert transform. Each AP was associated with the ongoing theta phase on the one hand and, on the other hand, to the current location of the animal in the linear track ( $x$ coordinates). Distance/phase correlations (cf. statistical analyses) were calculated using the circular statistics described by Fisher (1993).

The slope and direction of the mean phase as a function of distance in the field was calculated using a method similar to that of Huxter et al. (2003). We only performed linear regressions on data showing a significant circular-linear correlation. Circular data were unwrapped so that the totality of the data points fitted in a single plane. This unwrapping
$\mathrm{T}$
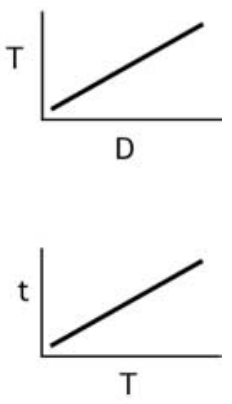

process was done recursively, by computing the distance of each point to the mean phase. Each point that was at a distance positively $>1.5 \mathrm{SDs}$ to the mean was offset by $-360^{\circ}$. The linear regression was then computed. This process was repeated 10 times, each step giving a slope, $y$-intercept, and least mean squares value. The lowest least mean square value (thus corresponding to the best unwrapping process) led to the slope value. The slopes of the phase distance relationship were only computed for significant correlations coefficients.

Compression index. The time compression index was defined, for all possible pairs of cells, as the ratio of two spike timing measures: (1) the time necessary for the animal to go from one field to the other, and (2) the equivalent compressed time in the theta domain (i.e., the time lag between the spikes of the two corresponding place cells within one theta cycle) (Geisler et al., 2007). It was computed for pairs of simultaneously recorded neurons that shared the same firing directionality, on the basis of their crosscorrelogram (CCG). For each pair, the associated cross-correlogram ( 3 ms bins) was filtered in "running time domain" $(0-1.5 \mathrm{~Hz})$ and in "theta time domain" $(0-20 \mathrm{~Hz})$. In the first type of filtered cross-correlogram (real time), the time lag between zero and the nearest peak corresponded to the traveling time between the two fields. In the second type, the time lag corresponds to the typical time interval between spikes of the two cells, within a theta cycle. The compression index corresponds to the correlation coefficient between these two sets of time lags in the whole population. We also computed the correlation between the time lag (in each domain) and the distance between the fields.

Theta modulation of unit activity. For each cell, the amplitude of theta modulation was assessed by multitaper spectral density estimates of the spike train. The amplitude of the signal was averaged in the theta band $(6-12 \mathrm{~Hz})$ and compared between the two groups. Oscillation frequency was determined on the basis of the time lag of the peak of the autocorrelogram filtered in the theta vicinity $(5-20 \mathrm{~Hz})$. To evaluate the influence of theta rhythm on interactions between pairs of cells, we performed spectral analyses (based on the Welch method) on each normalized cross-correlogram. Theta average amplitude (the average power in the theta band), theta maximal amplitude and frequency, and theta score (total amplitude in the theta band divided by the total amplitude in the whole power spectrum from 1 to $60 \mathrm{~Hz}$ ) were computed.

Morris water maze. The water maze procedure was similar to that used previously in our laboratory (Liu et al., 2003). The procedure started after completion of electrophysiological testing. The apparatus consisted of a stainless-steel circular swimming pool $(2 \mathrm{~m}$ in diameter, $50 \mathrm{~cm}$ high $)$ filled to a depth of $25 \mathrm{~cm}$ with water. White paint was added to make the water opaque and prevent the rats from seeing the platform. Room cues visible from the water surface were constant from day to day. Four points on the perimeter of the pool were designated north $(\mathrm{N})$, south $(\mathrm{S})$, east (E), and west (W), thus dividing the pool into four quadrants (NW, NE, SE, SW). A clear Plexiglas escape platform $8 \mathrm{~cm}$ in diameter was positioned in the center of one of the quadrants, $1 \mathrm{~cm}$ below the water surface. The rats underwent testing in the water maze for $7 \mathrm{~d}$. On day 1 , each rat was placed in the pool for $60 \mathrm{~s}$ without the platform present; this free swim enabled the rat to become habituated to the training environment. On days 2-6, rats were trained for 24 trials (six trials a day) to locate and escape onto the submerged platform. For each rat, the quadrant in which the platform was located remained constant for the duration of the experiment, but the point of immersion into the pool varied between $\mathrm{N}, \mathrm{E}$, $\mathrm{S}$, and $\mathrm{W}$ in a random order for each trial so that the rat was not able to predict the platform location from the point at which it was placed in the pool. The latency from immersion into the pool to escape onto the plat- 
Table 1. Place cell measurements and statistics ( $t$ values and significance) for CTR and SE cells

\begin{tabular}{lccrc}
\hline Cell property & \multicolumn{1}{l}{ CTR } & \multicolumn{1}{l}{ SE } & \multicolumn{1}{l}{$t$} & \multicolumn{1}{l}{$p$} \\
\hline Coherence & $0.692 \pm 0.03$ & $0.608 \pm 0.03$ & -2.22 & 0.03 \\
Information content (bits) & $1.39 \pm 0.10$ & $1.13 \pm 0.06$ & -2.26 & 0.03 \\
Global rate (Hz) & $1.58 \pm 0.17$ & $1.69 \pm 0.19$ & 0.42 & 0.67 \\
In-field rate (Hz) & $5.19 \pm 0.53$ & $4.96 \pm 0.53$ & 0.31 & 0.75 \\
Peak rate (Hz) & $26.44 \pm 5.78$ & $33.55 \pm 6.52$ & 0.78 & 0.43 \\
Out-of-field rate (Hz) & $1.24 \pm 0.16$ & $1.34 \pm 0.17$ & 0.41 & 0.68 \\
Field length $(\mathrm{cm})$ & $35.21 \pm 1.93$ & $36.68 \pm 1.98$ & 0.53 & 0.60 \\
\hline
\end{tabular}

form was recorded for each trial, and the observer also manually recorded the route taken by the rat to reach the platform. All trials were also videotaped for subsequent analysis of swimming path. On mounting the platform, the rats were given a $30 \mathrm{~s}$ rest period, after which the next trial was started. If the rat did not find the platform in $120 \mathrm{~s}$, it was manually placed on the platform for a $30 \mathrm{~s}$ rest. At the start of each trial, the rat was held facing the perimeter and dropped into the pool to ensure immersion. For each trial, latency to reach the platform was recorded. One day after completion of the last latency trial (day 7), the platform was removed and animals were placed in the water maze for $2 \mathrm{~min}$ in the quadrant opposite that in which the platform had previously been located. The path and time spent in the quadrant where the platform had previously been placed were recorded. In this part of the water maze, termed the probe test, normal animals typically spend more time in the quadrant where the platform had been previously located than in the other quadrants. Animals were videotaped during the testing, and swimming pathway, time to escape platform, and swimming speed were analyzed off-line using an automated tracking system (ANY-Maze; Stoelting, Wood Dale, IL).

Histology. At the end of the experiment, rats were administered a lethal dose of sodium pentobarbital $(65 \mathrm{mg} / \mathrm{kg})$ and perfused transcardially with $200 \mathrm{ml}$ of normal saline, $200 \mathrm{ml}$ of sodium sulfide medium $(2.925$ gm of $\mathrm{Na}_{2} \mathrm{~S}$ and $2.975 \mathrm{gm}$ of $\mathrm{NaH}_{2} \mathrm{PO}_{4} \cdot \mathrm{H}_{2} \mathrm{O}$ in $500 \mathrm{ml}$ of $\mathrm{H}_{2} \mathrm{O}$ ), and 200 $\mathrm{ml}$ of $4 \%$ paraformaldehyde (PFA). The brains were removed, postfixed in $4 \%$ PFA for $24 \mathrm{~h}$, and placed in $30 \%$ sucrose for $24 \mathrm{~h}$ or longer until the brains sank. Coronal sections along the entire extent of the hippocampus were cut at $30 \mu \mathrm{m}$ on a freezing microtome and stored in PBS. Every second section was Timm stained for mossy fibers and every third section for thionin.

For Timm staining, sections were developed in the dark for 40-45 min in a solution of $50 \%$ gum arabic $(120 \mathrm{ml}), 10 \mathrm{ml}$ of citric acid $(51 \mathrm{gm} / 100$ $\left.\mathrm{ml} \mathrm{H}_{2} \mathrm{O}\right), 10 \mathrm{ml}$ of sodium citrate $\left(47 \mathrm{gm} / 100 \mathrm{ml} \mathrm{H}_{2} \mathrm{O}\right), 3.47 \mathrm{gm}$ of hydroquinone in $60 \mathrm{ml}$ of $\mathrm{H}_{2} \mathrm{O}$, and $212 \mathrm{mg}$ of $\mathrm{AgNO}_{3}$. Slides from control and SE rats were always stained at the same time. After washing, the slides were dehydrated in alcohol, cleared in xylene, and sealed with Permount.

Timm-stained sections were analyzed using a semiquantitative scale for terminal sprouting in CA3 and the supragranular region (Holmes et al., 1998, 1999). Timm staining in the pyramidal and infrapyramidal CA3 region and supragranular region was assessed on each section from the septal area in which the two blades of the dentate were equal and formed a $V$ shape $(2.8 \mathrm{~mm}$ posterior from the bregma) to a point $3.8 \mathrm{~mm}$ posterior to the bregma (Paxinos and Watson, 1998). Assessment of the Timm score in the supragranular region was done in the inferior blade of the dentate, avoiding the edge and crest of the gyrus. Both hippocampi of the specimens were analyzed, and the score given to the CA3 and supragranular regions reflected the mean for the two sides. Five sections per rat were evaluated. A five-point scale was used to assess staining, with 0 indicating no staining and 5 equaling intense, homogeneous staining.

Thionin-stained slides were used to assess cell loss. CA1, CA3, and the hilus were graded separately on the following scale: 0 , no cell loss; 1 , cell loss $<25 \%$; 2 , cell loss $25-50 \%$; 3 , cell loss $50-75 \%$; 4, no remaining cells (Mikati et al., 1994; Schmid et al., 1999). Values for each region were taken as averages for the two hippocampi.

Statistical analyses. All place cell properties (Table 1), as well as cluster quality measures ( $L_{\text {ratio }}$ and isolation distance) and unit theta oscillation
Table 2. Average EEG theta frequency and animal speed during running periods (the first recording session for each rat)

\begin{tabular}{llcll}
\hline & CTR & SE & $t_{(9)}$ & $p$ \\
\hline Theta frequency $(\mathrm{Hz})$ & $7.81 \pm 0.105$ & $7.28 \pm 0.169$ & 2.54 & 0.031 \\
Speed $(\mathrm{cm} / \mathrm{s})$ & $23.0 \pm 1.86$ & $17.72 \pm 1.40$ & 2.32 & 0.045 \\
Theta frequency at $22 \mathrm{~cm} / \mathrm{s}(\mathrm{Hz})$ & $7.66 \pm 0.093$ & $7.30 \pm 0.206$ & 1.62 & 0.14 \\
\hline
\end{tabular}

frequency were compared using a $t$ test. Because it results from a correlation coefficient, coherence data were normalized using the Fisher transform. Theta oscillation frequency was analyzed as a function of running speed using a two-way repeated-measures ANOVA. Results were considered statistically significant if the value of $p \leq 0.05$.

Distance/phase correlations were calculated for each individual cell, using the circular statistics described by Fisher (1993) as follows: $R^{2}=$ $\left(r^{2}{ }_{12}+r^{2}{ }_{13}-r_{12} r_{13} r_{23}\right) /\left(1-r^{2}{ }_{23}\right)$, where $r_{12}=r\left[\left(x_{1}, \cos \theta_{1}\right), \ldots,\left(x_{n}\right.\right.$, $\left.\left.\cos \theta_{n}\right)\right] ; r_{13}=r\left[\left(x_{1}, \sin \theta_{1}\right), \ldots,\left(x_{n}, \sin \theta_{n}\right)\right] ; r_{23}=r\left[\left(\cos \theta_{1}, \sin \theta_{1}\right), \ldots\right.$, $\left.\left(\sin \theta_{n}, \cos \theta_{n}\right)\right] ; x$ and $\theta$ corresponding to the animal position and theta phase, respectively. The significance of this coefficient (Mardia and Jupp, $2000)$ is determined by the following: $Z=\left[(N-3) R^{2}\right] /\left(1-R^{2}\right)$, which is distributed under the null hypothesis as $F$ with 2 and $N-3$ degrees of freedom.

Coefficient correlations (Fisher transform) and slopes were compared between the two populations (SE and CTR) using a $t$ test.

For the compression analyses, correlation coefficients between CCG running time lag, theta time lags, and interfield distance were compared between CTR and SE using a $Z$ test. Variation about the regression line was calculated as described by Bailey (1995). Average running speed, estimated over one session per animal (every $400 \mathrm{~ms}$ ), was compared using a $t$ test.

In the water maze, time to reach the escape platform was compared using a repeated-measures ANOVA with two factors (treatment and session number). On the probe test, a $\chi^{2}$ test was used to determine whether the animals spent an equal time in the four quadrants.

\section{Results}

Place cells and hippocampal EEG and units were recorded from five controls (CTR) and six SE rats as they were running back and forth on a linear track for a food reward (Fig. 1A). Spontaneous behavioral seizures occurred at least once in three of six $(50 \%)$ of the SE rats but were never seen in the five control rats. Seizure frequency was low with rats having one to two seizures per day. We did not proceed with recording if seizures were seen in the $2 \mathrm{~h}$ before the recording session. No rats had electroencephalographic or behavioral seizures during the recording sessions. Thus, the place cell activity described next was measured in the absence of behaviorally or electroencephalographic seizures. Similar precautions were taken while later assessing water maze performance of these rats. Interictal spikes (IS) were observed in four of six $(66.7 \%)$ of rats and were present in all three rats with spontaneous seizures. As documented by Buzsaki et al. (1989), IS were rarely observed during periods of high activity/high theta and were more common while eating or pausing (at the end of the shuttle) or during slow wave sleep. No IS were observed while the animals were performing the shuttle behavior and therefore IS had no direct effect on phase precession.

Among the 310 pyramidal cells recorded in six SE rats, 174 (56\%) were characterized as place cells (see Materials and Methods). In the CTR group (five rats), 150 (42\%) of the 259 recorded pyramidal cells were place cells. In maze-like environments, where the movements of the animal are restricted to two directions, place cells tend to fire differently according to the directions of the animal (McNaughton et al., 1983). Some cells can have one field in one direction only, some have the same field slightly offset from one direction to the other, and some can have 
Table 3. Unit oscillation frequency, ongoing EEG frequency, and their correlation

\begin{tabular}{lllll}
\hline & $\begin{array}{l}\text { Cell oscillation } \\
\text { frequency (average; in Hz) }\end{array}$ & $\begin{array}{l}\text { EEG theta frequency } \\
\text { (average; in Hz) }\end{array}$ & Correlation $(r)$ & $p$ \\
\hline $\operatorname{CTRL}(n=52)$ & $8.01 \pm 0.155$ & $7.53 \pm 0.039$ & 0.557 & $\leq 0.0001$ \\
SE $(n=65)$ & $7.62 \pm 0.122$ & $7.26 \pm 0.067$ & 0.556 & $\leq 0.0001$ \\
\hline
\end{tabular}

Average oscillation frequency was calculated for the cells used in phase precession analysis. This measure was correlated to the EEG theta frequency recorded during the same session ( $r$, correlation coefficient; $p$, probability of nonsignificant correlation).

\section{Table 4. Individual data}

\begin{tabular}{llllll}
\hline Rat ID & E1 & E2 & E4 & E5 & E7 \\
\hline No. cells & 23 & 21 & 8 & 8 & 5 \\
Distance/phase $r$ & $-0.253 \pm 0.055$ & $-0.302 \pm 0.055$ & $-0.267 \pm 0.113$ & $-0.268 \pm 0.088$ & $-0.224 \pm 0.081$ \\
Slope $m$ & $-1.54 \pm 0.65$ & $-2.61 \pm 0.62$ & $0.27 \pm 0.98$ & $-1.80 \pm 0.57$ & $-0.98 \pm 0.76$ \\
$\%$ NS & $35 \%$ & $22 \%$ & $63 \%$ & $13 \%$ & $80 \%$ \\
Coherence & $0.604 \pm 0.050$ & $0.661 \pm 0.047$ & $0.549 \pm 0.061$ & $0.625 \pm 0.053$ & $0.462 \pm 0.031$ \\
$\theta$ Frequency (Hz) & $6.8 \pm 0.04$ & $7.57 \pm 0.04$ & $7.02 \pm 0.09$ & $7.66 \pm 0.10$ & $7.89 \pm 0.16$ \\
Speed (cm/s) & $17.9 \pm 0.89$ & $18.89 \pm 0.64$ & $19.26 \pm 0.92$ & $21.61 \pm 0.98$ & $24.38 \pm 2.29$ \\
WM accuracy & $24 \%$ & $80 \%$ & $24 \%$ & $34 \%$ & $62 \%$ \\
Epilepsy & IS & & IS + SZ & IS + SZ & IS \\
\hline
\end{tabular}

Data are expressed as mean and SD. $N$, Number of cells analyzed for phase precession; $r$, average distance-phase correlation; $m$, slope of the phase-distance regression line; \% NS, percentage of cells with nonsignificant $r$ value; WM accuracy, percentage of time spent in the platform zone during probe test in the water maze; epilepsy, state of epilepsy impairment; IS, witnessed interictal spikes; $S Z$, witnessed seizures (E3 is not represented here because no place cell met the requirements for phase precession analysis).

two distinctly different fields, depending on the direction traveled. We thus concentrated our analysis on centrally located fields (17 $\mathrm{cm}$ away from either end of the track) and performed unidirectional firing maps along the $x$ dimension, one map per direction. As in a previous study (Liu et al., 2003), we observed that SE place cells have a lower coherence (one-dimension coherence, SE, $0.608 \pm 0.026$; CTR, $\left.0.692 \pm 0.026 ; t_{(123)}=-1.93 ; p=0.028\right)$ and information content (SE, $1.13 \pm 0.06$; CTR, $1.39 \pm 0.10$; $t_{(123)}=-2.26 ; p=0.03$ ) than CTR rats. In addition, we found that SE cells tended to fire more in two directions than CTR cells, as characterized by a lower directionality index (SE, $0.403 \pm$ 0.036 ; CTR, $\left.0.517 \pm 0.033 ; t_{(123)}=-2.26 ; p=0.013\right)$. Other parameters, including field length (in the $x$ dimension) and firing rate (Table 1) did not differ between the two groups. Cell isolation quality (Schmitzer-Torbert et al., 2005) (i.e., the quality of cluster cutting) was not significantly different between SE and CTR in terms of cluster quality $\left(L_{\text {ratio }}: \mathrm{SE}, 0.418 \pm 0.065\right.$; CTR, $0.303 \pm 0.047 ; t_{(123)}=1.402 ; p=0.16$; isolation distance: $\mathrm{SE}$, $23.5 \pm 2.411$; CTR, $\left.29.6 \pm 3.926 ; t_{(123)}=1.36 ; p=0.18\right)$. In summary, these results demonstrate that firing patterns of place cells from SE were mildly altered compared with controls.

We then compared theta frequency and running speed between CTR and SE rats (Table 2). To exclude from the analysis all periods of low theta signal (when the rat was eating, at either end of the track), we only analyzed segments of data associated with speeds $>2 \mathrm{~cm} / \mathrm{s}$. As shown in Table 2, both speed and theta frequencies were lower in the SE rats than the CTR. It is known that theta frequency is influenced by speed (Vanderwolf, 1969). To dissociate these two variables, we compared theta frequencies in sessions with equivalent speeds (one session per animal, speeds averaging $\sim 22 \mathrm{~cm} / \mathrm{s}$ ). In this case (Table 2 ), theta frequency did not differ between groups (CTR, $7.66 \pm 0.093 \mathrm{~Hz}$; SE, $7.30 \pm$ $0.206 \mathrm{~Hz} ; t=1.62 ; p=0.14$; speeds: CTR, $22.13 \pm 1.92 \mathrm{~cm} / \mathrm{s} ; \mathrm{SE}$, $21.86 \pm 2.345 \mathrm{~cm} / \mathrm{s} ; t=0.103 ; p=0.92$ ). Thus, running speed, but not theta frequency per se is affected in SE rats.

To investigate the relationship between place cell firing frequency and the ongoing EEG theta frequency, we analyzed phase versus rate relationships for both SE and CTR cell populations. As shown in supplemental Figure $\mathrm{S} 1 A$ (available at www. jneurosci.org as supplemental material), phase modulation was similar in SE and CTR cells. We also compared the oscillation frequency of each cell to the ongoing EEG theta rhythm in the same recording session. In both CTR and SE cells, there was a significant correlation between the intrinsic cell oscillation and the ongoing theta frequency during the session (Table 3). For individual data, see Table 4.

We assessed phase precession quality by computing the phase-distance correlation coefficient ( $c$-linear association) (Fisher, 1993) of the first 150 APs of each neuron in both groups (cells firing $<150$ APs in their field were discarded from this analysis). We found that SE place cells had a significantly lower distance/phase correlation than controls (SE, $0.246 \pm 0.033$; CTR, $0.366 \pm 0.017 ; t_{(115)}=2.73 ; p=$ $0.007)$, indicating that there was a disturbance in phase precession in SE rats. Figure 3 shows examples of phase precession patterns in both CTR (top row) and SE rats (precessing, middle row; non-precessing cells, bottom row). Although the circular-linear correlation coefficient appears to be the most appropriate way to assess the quality of phase precession, it does not provide a direction of the correlation. Although for some cells the distance/phase correlation was significant, the direction of the correlations was not consistently in the expected direction (i.e., phase increased as a function of distance instead of decreasing) (two examples of such cells is displayed in Fig. 3, bottom left corner). We thus analyzed the slope of the mean phase $(m)$ and its direction as a function of distance in the field using a similar method as Huxter et al. (2003). We only performed linear regressions on data showing a significant circularlinear correlation. SE slopes were significantly lower than the CTR (SE: $m=-2.28 \pm 0.393 \% \mathrm{~cm}, 48$ cells; CTR: $m=-3.25 \pm$ $0.345^{\circ} / \mathrm{cm}, 50$ cells; $t_{(96)}=1.857, p=0.033$, unilateral test). In the SE group, six cells $(13.3 \%)$ had a positive slope. This was never observed in the control group. In conclusion (Fig. 4), a greater proportion of SE place cells had no significant or opposite distance/phase correlation (SE, 35.4\%; CTR, 3.8\%; $\chi^{2}=17.10 ; p<$ $0.0001)$. Similarly, we compared distance-phase correlations for population of cells in both groups (supplemental Fig. S1 $B$, available at www.jneurosci.org as supplemental material). These correlations were based on 45 randomly chosen cells per group, each cell contributing 45 APs. The position of the rat in the field was normalized ( 0 being the beginning of the field and 1 being the end) and the firing phase of each cell was aligned to its average firing phase in the first third of the field. We found a weaker phase distance correlation in SE rats than in controls (CTR, $r=0.333$; SE, $r=0.279 ; Z=1.87 ; p=0.039$ ). These findings show that there is a substantial disturbance in the timing of place cell firing in relationship to theta activity.

Interestingly, we observed that simultaneously recorded cells were not affected the same way in terms of phase precession. Some cells showed a significant distance/phase correlation, whereas other, neighboring, simultaneously recorded cells did not. An example of this phenomenon is shown in Figure 3, where the plots with an asterisk correspond to simultaneously recorded cells.

It is important to note that, in the SE group, place field coher- 

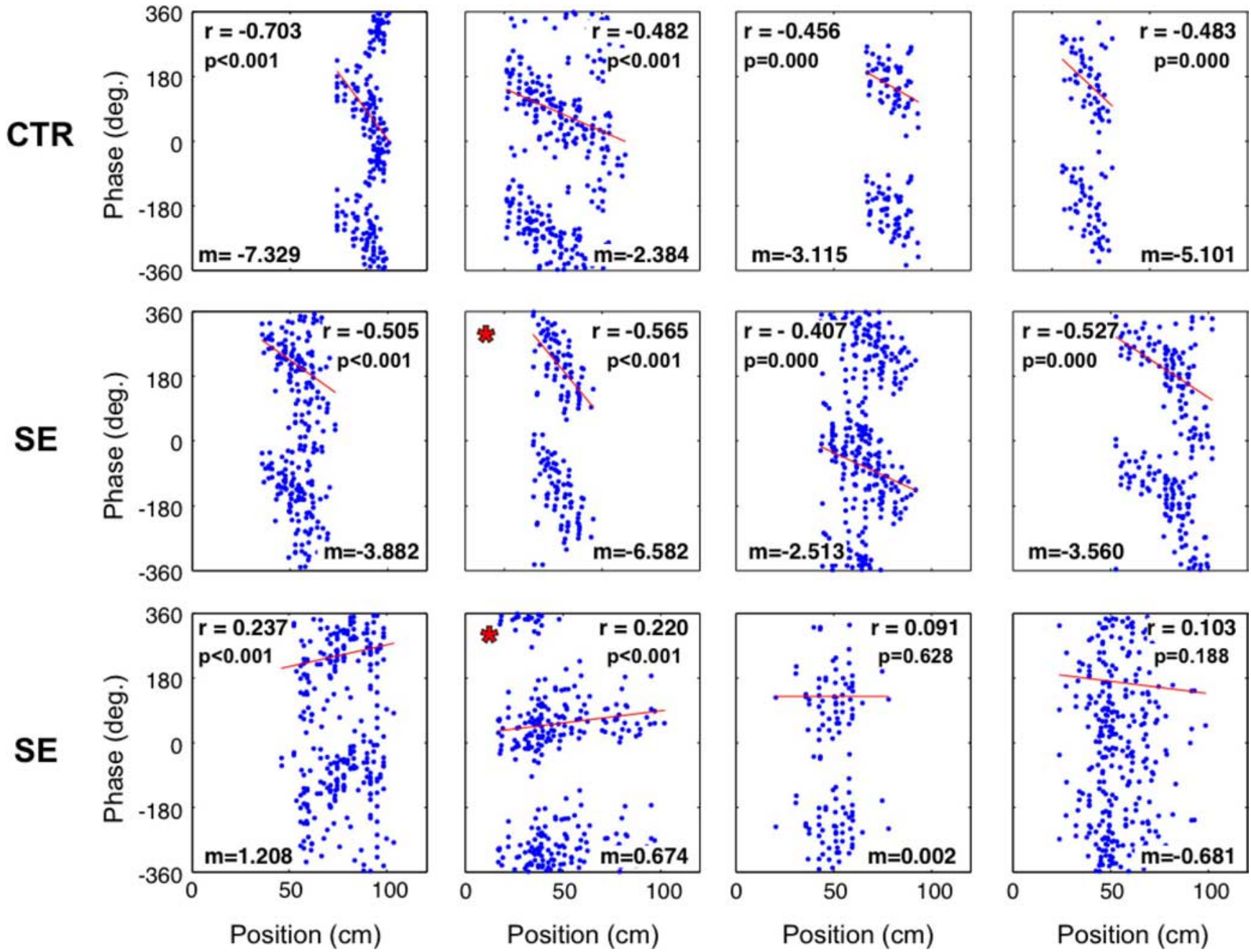

Figure 3. Distance versus phase plots of characteristic cells in CTR (top row) and SE rats (two bottom rows). Like CTR cells, some SE cells (middle row) display significant distance/phase correlation coefficients $(r)$. However, a great proportion of the cells (bottom row) show aberrant patterns ( $m$, slope of the distance/phase relationship; $p, p$ value). Plots with an asterisk denote cells recorded simultaneously.
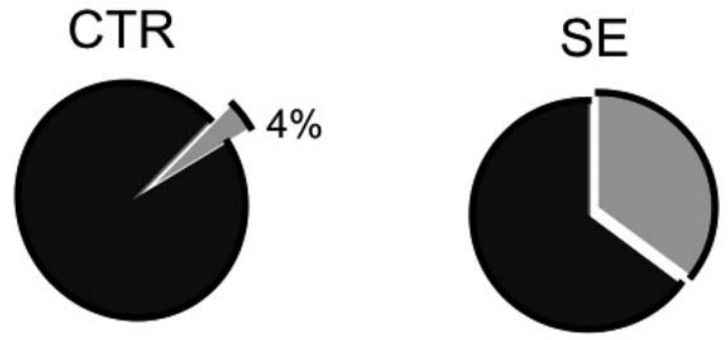

$35 \%$

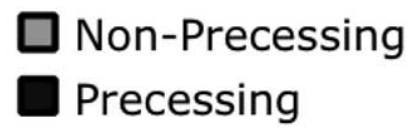

Figure 4. Phase precession is altered in SE rats: proportion of place cells showing significant and nonsignificant distance-phase correlation coefficients and/or opposite slopes in CTR and SE cells.

ence did not differ between cells with and without significant correlation coefficients (significant $r$ values: $0.620 \pm 0.030$; nonsignificant $r$ values and opposite precession patterns: $0.586 \pm$ $0.140, t_{(63)}=-0.61, p=0.55$, NS). Thus, it is unlikely that the spatial signal impairment observed in SE rats is responsible for the altered phase precession.
To maintain phase precession, the intrinsic cell firing frequency needs to increase above theta frequency by an amount proportional to running speed (Burgess et al., 2007). We thus examined the possibility that increased variability in running speed could affect phase precession measures. To do so, we computed, in SE cells, the correlation between phase precession $r$ values (corrected by Fisher transform) for each cell and the speed variability during the recording session, assessed from trial to trial, in the preferred firing direction of the cell. We did not find a significant correlation $(r=0.097 ; p=0.44)$ suggesting speed variability did not play a role in altered phase precession.

The correlation (Fig. 2) between the time spent by the animal traveling between two place fields and the time interval between the spikes of the two cells within one theta cycle (Skaggs et al., 1996) (i.e., the correlation between CCG time lags in running and theta time) is called the compression index (Dragoi and Buzsaki, 2006). Figure 5 shows examples of CCGs of three pairs of cells for CTR (top) and SE rats (bottom). For each pair, the CCG is displayed twice, once per timescale (top row, running time; bottom row, theta time scale). As can be seen on CTR examples, the lag observed in the theta time is approximately one-tenth of the lag observed in the running time. In contrast, a portion of SE pairs have unproportional relationships. 


\section{CTR}

Pair 1
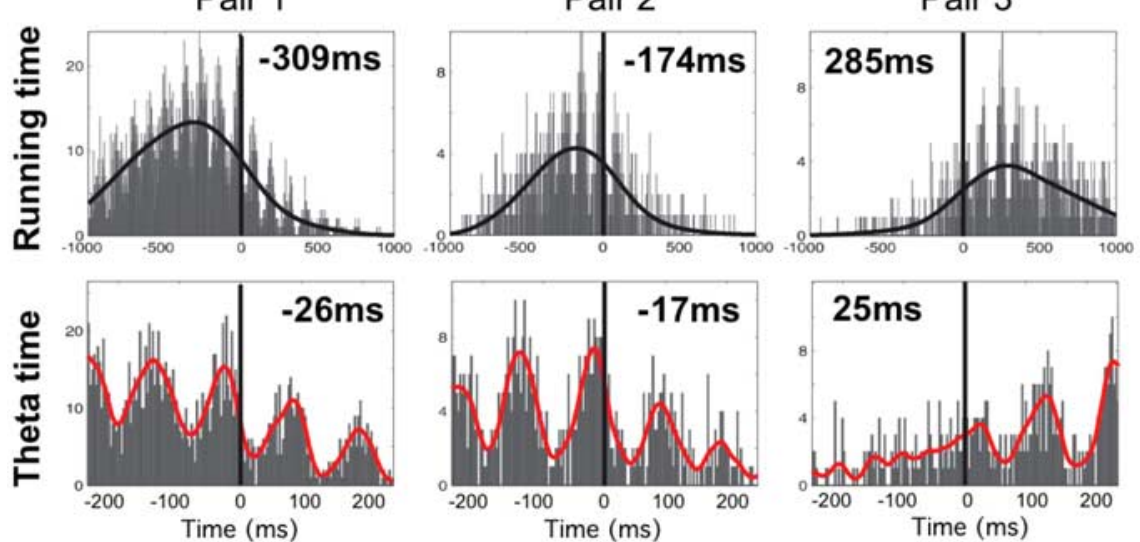

SE

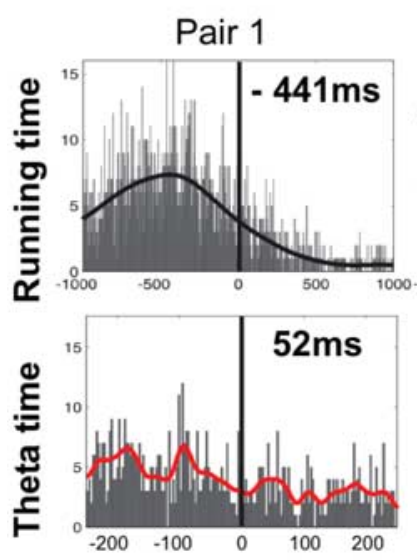

Pair 2
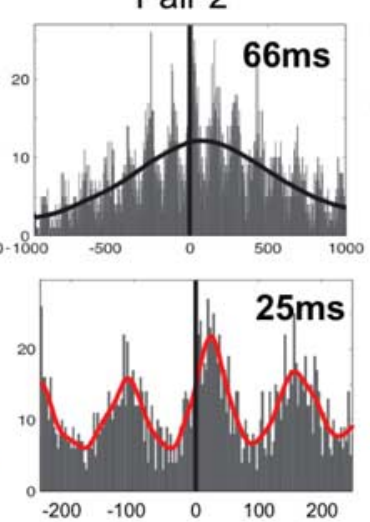

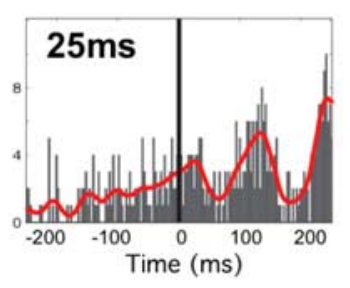

Pair 3

Figure 5. Examples of CCGs of three pairs of cells for CTR (top) and SE rats (bottom). For each pair, the CCG is displayed twice, once per timescale (top row, running time; lower row, theta time scale). As can be seen on CTR examples, the lag observed in the theta time $(t)$ is approximately one-tenth of the lag observed in the running time ( $T$ ). In contrast, a greater proportion of SE pairs do not have proportional relationships.

Plots of theta time lag as a function of running time lag are shown on Figure $6 \mathrm{~A}$ for both SE and CTR pairs. Strikingly, in some of the SE pairs (44\%), the CCG theta time lag was observed at different values than predicted by the running time. Although running/theta lag Spearman correlation coefficients $(\rho)$ were statistically significant for both groups (CTR, 38 pairs, $\rho=0.828$, $p<0.0001$; SE, 36 pairs, $\rho=0.788, p<0.0001$ ) and did not differ from each other $(Z=0.046 ; p=0.63$, NS), SE pairs showed a greater variability around the regression line than CTR ones (variance around the regression line: CTR, 411.03; SE, 2203.28; $\left.F_{(37,35)}=5.36 ; p<0.0001\right)$. Likewise, interfield distance/theta lag correlations were significant for both groups (CTR: 38 pairs, $r=$ 0.761, $p<0.0001$; SE: 36 pairs, $r=0.750, p<0.0001)$ and did not differ $(Z=0.013$; $p=0.92$, NS), but SE pairs showed a bigger variability around the regression line (SE, 1260.96; CTR, 434.38; $\left.F_{(35,37)}=2.9028 ; p=0.003\right)$. There was no difference in interfield distance/running-time lag correlations (CTR: $r=0.868, p<$ 0.0001; SE: $r=0.938, p<0.0001$; CTR-SE comparison: $Z=$ $-0.077, p=0.11, \mathrm{NS})$, and no difference in terms of variability $\left(\mathrm{SE}: \sigma=41454.55\right.$; CTR: $\sigma=31049.131 ; F_{(35,37)}=1.34 ; p=0.61$, NS). These results are all the more important that, in contrast to

real-time spiking lag, interfield distance is not influenced by behavioral variability (Geisler et al., 2007).

Another way of displaying this compression abnormality is provided in Figure $6 B$, in which normalized CCGs (filtered in the theta band) of both groups are sorted in increasing running-time lag ( $y$-axis). The $x$-axis represents the time lag $(t)$ and the color code represents the CCG amplitude, in normalized units. In CTR pairs, the central peak (nearest to $0 \mathrm{~ms}$ lag) forms a clear diagonal that shifts toward the left as the running time lag increases. In contrast, in SE pairs, this pattern is not present.

The strength of theta modulation in the joint firing of pairs of neurons was compared between SE and CTR rats. We performed power spectral analysis of normalized CCG of each pair of neurons and found no difference in terms of theta amplitude (CTR, 5.23E-3 \pm 0.79E-3; SE, 4.6E-3 \pm $0.89 \mathrm{E}-3$ normalized units ${ }^{2} / \mathrm{Hz} ; t_{(72)}=$ $-0.77 ; p=0.44, \mathrm{NS}$ ) and theta score (CTR, $0.477 \pm 0.030 ; \mathrm{SE}, 0.442 \pm 0.034 ; t_{(72)}=$ $-0.54 ; p=0.60$, NS) between SE and CTR pairs. However, the oscillation frequency of their CCGs differed significantly in the two groups (CTR, $8.51 \pm 0.124 \mathrm{~Hz}$; SE, $7.805 \pm$ $\left.0.159 \mathrm{~Hz} ; t_{(72)}=3.496 ; p<0.001\right)$. In other words, SE pairs joint firing oscillated at a comparable theta amplitude and strength but at a lower frequency than CTR cells.

After completion of the recordings, SE and CTR rats were trained in the water maze task for 5 consecutive days (six trials daily). Although it took $4 \mathrm{~d}$ for the controls to reach maximum performance (escape latency of $15 \mathrm{~s}$ ), SE rats never learned the task (Fig. 7A). ANOVA of the escape latency to reach the platform reveals a significant day effect $\left(F_{(3,192)}=32.6967 ; p<0.0001\right)$, treatment effect $\left(F_{(1,64)}=31.89 ; p<0.0001\right)$ as well as a significant day/treatment interaction $\left(F_{(3,192)}=5.25 ; p=0.002\right)$. On the sixth day, the platform was removed and the rats were allowed to swim for $2 \mathrm{~min}$ (Fig. $7 B$ ). In contrast to CTR rats, which swam more in the platform quadrant $\left(\chi^{2}=16.0 ; \mathrm{df}=3 ; p=0.0011\right)$, SE rats did not show any preference for any quadrant $\left(\chi^{2}=\right.$ $0.048 ; \mathrm{df}=3 ; p=0.75)$. In summary, SE rats were impaired in learning the water maze task.

Animals were then killed and the brain analyzed for cell loss and synaptic reorganization using previously described scales (Rutten et al., 2002). The nonparametric Mann-Whitney test was used to compare cell loss and Timm scores (ranging from 0 to 5, where 5 is the darkest possible staining) (see Materials and Methods). A modest degree of cell loss was seen in the CA3 and dentate gyrus (DG), but not CA1 of the SE rats (CA1: SE, $-1.35 \pm 0.33$; $\mathrm{CTR},-0.55 \pm 0.34 ; p=0.393$; CA3: SE, $-1.42 \pm 0.30$; CTR, $-0.20 \pm 0.20 ; p=0.036$; DG: SE, $-1.67 \pm 0.33$; CTR, $-0.20 \pm$ $0.20 ; p=0.036$ ). Timm staining was also modestly increased in the inner molecular layer of the dentate gyrus and infrapyramidal layer of the CA3 subfield (supragranular region: $\mathrm{SE},-1.83 \pm$ 
0.44; CTR, $-0.20 \pm 0.20 ; p=0.036$; CA3: $\mathrm{SE},-1.5 \pm 0.29 ; \mathrm{CTR},-0.20 \pm 0.20 ; p=$ $0.009)$.

\section{Discussion}

The aim of this study was to determine whether temporal coding by hippocampal pyramidal neurons could be altered in a pathological state affecting hipocampal connectivity and structure. We used MTLE as a tool to investigate hippocampal coding alterations. This model is of particular interest because it induces significant, but partial hippocampal damage, and has already been showed to alter, but not abolish place cell firing. Our major finding is that, in SE rats, phase precession was not observed in a great proportion of cells. As a consequence, the compression of temporal sequences was disrupted.

As in a recent experiment by Liu et al. (2003) we observed that SE pyramidal cell spatial activity was affected. Fields were less precise spatially and less directional than CTR in the linear track. The deficits we observed were milder than those reported in Liu et al. (2003). This could be explained by two factors. First, our rats were less dramatically affected by the SE induction than in their experiment. Spontaneous seizures were less frequent and of shorter duration than in the study by Liu et al. (2003). Second, the relatively simple geometry of the linear track, compared with the circular arena used by Liu et al. (2003), could have helped to support place cell coding by restricting the displacement possibilities of the animal. Furthermore, despite the modest cell loss and synaptic reorganization, the SE rats in this study had dramatic deficits in the water maze task. Although the design of our experiment does not allow us to draw any direct causality between the electrophysiological and behavioral findings, it is possible that the temporal coding abnormalities observed in SE rats played an important role in those impairments.

Temporal coding (i.e., the way neurons process information in time and interact with each other) is believed to be crucial for normal cognitive function. In the hippocampus, temporal coding, driven by neural oscillations such as theta rhythm, is characterized by phase precession. Such phenomenon is proposed to provide two types of information to the system. First, the phase of each action potential gives more precise information about the current location of the animal in the field of the cell, thus in the environment. Second, at the multiunit level, phase precession provides critical information about distance and relative time order of cell activation. Phase precession drives neurons with partially overlapping fields to fire at a particular time interval within the same theta wave, regardless of where the animal is located in the corresponding fields. Because this time interval is directly related to both the distance between the fields and the time order in which the cells are activated, it is proposed that phase precession provides the system with a way to compress, in a time window relevant for synaptic plasticity, the temporal sequence of the locations visited by the animal. Although such a role of phase precession in cognitive process remains hypotheti-
CTR

SE

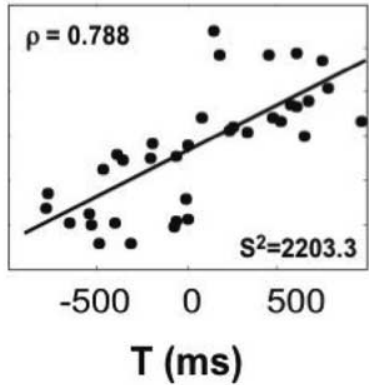

SE Theta Lag (ms)

\section{CTR}

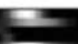

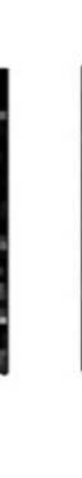

\section{Theta Lag (ms)}

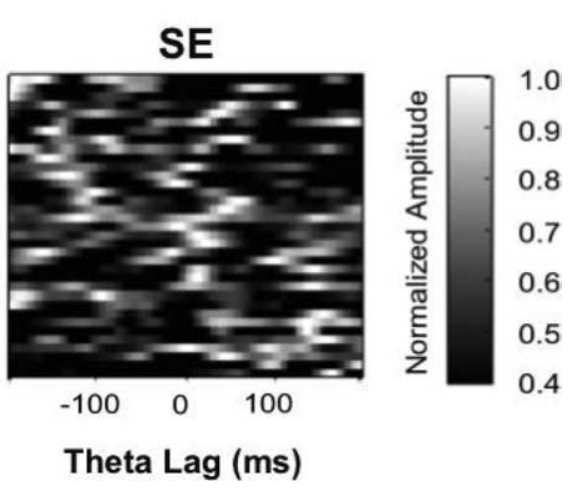

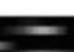

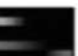

Figure 6. Abnormal compression of temporal sequences in SE rats. $A$, In contrast to CTR pairs of neurons, which show a strong correlation between running-time $(T)$ and theta-time lags $(t)$, SE pairs showed a greater variability as expressed by the total variance about the regression line $\left(S^{2}\right) . \rho$, Spearman correlation coefficients. $B$, CCGs for all CTR and SE pairs ordered in increasing mplitude represented by a color code. In CTR pairs, the diagonal band near the zero lag line shifts to the left as running-time lag increases. In contrast, this pattern is much less obvious in SE pairs.

cal, our results strongly suggest a functional role of phase precession in spatial memory.

At the synapse level, temporal coding as displayed by hippocampal neurons is of particular significance. First, induction of both LTP and long-term depression has been shown to depend on the temporal order of presynaptic and postsynaptic spiking (for review, see Dan and Poo, 2006). Second, two or more inputs are more likely to induce a neuron to discharge if they occur in a short time window (Agmon-Snir et al., 1998). The spatialtemporal organization of inputs on the dendritic tree influences greatly their postsynaptic processing (Johnston et al., 2003). As a consequence, synaptic plasticity is dependent on the spike activation sequence, which allows the coding of the sequential organization of internal and external events or episodes. A disturbance of temporal coding such as the one we observed should have dramatic consequences in term of their consolidation.

In a wider network point of view, and as noted by Buzsaki (2007), the consequences of hippocampal timing errors can be devastating when they are propagated across hippocampal-cortical pathways. The contrast between the severity of the behavioral deficits we observed in the water maze and the mild effect observed both on the histology and the unit firing supports this idea. A myriad of changes occur in the brain of rodents and after $\mathrm{SE}$ and it is not possible to state that abnormal temporal coding is responsible for the markedly impaired deficits in spatial memory seen in this study. However, alteration of the compression of temporal sequences, for example the sequence of places visited before reaching the platform, is likely to affect the whole learning process occurring during water maze acquisition in the hip- 

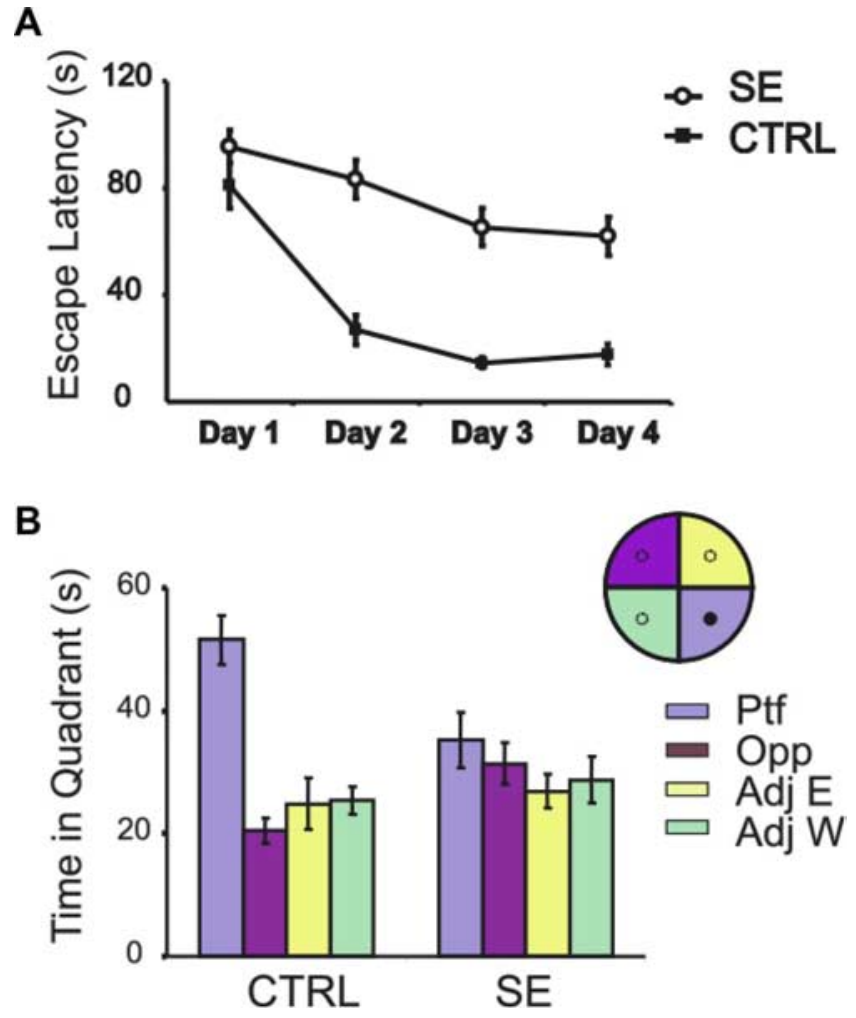

Figure 7. Water maze task. A, Learning curves of the SE and CTR rats used for place cell recording. After SE, rats had markedly impaired learning. $\boldsymbol{B}$, Probe trial with the platform removed. Control rats spend more time in the platform quadrant. In contrast, $S E$ rats did not show a preference for any specific quadrant (Ptf, Opp, Adj E, Adj W: platform, opposite, adjacent east, and adjacent west quadrants, respectively).

pocampal and associated network. Compared with the modest impairment in place cell firing patterns and limited histological damage, the abnormalities in phase precession seen here were quite pronounced, strongly suggesting that impaired temporal coding plays an important role in cognitive deficits after status epilepticus.

Several morphological and structural changes could account for the phase precession abnormalities we observed. In the adult animal, SE causes neuronal loss in hippocampal fields CA1, CA3, and the dentate hilus (Ben-Ari, 1985). In addition to cell death, prolonged seizures in the adult brain leads to synaptic reorganization with aberrant growth (sprouting) of granule cell mossy fibers in the supragranular zone of the fascia and infrapyramidale region of CA3 (Sutula et al., 1988; Represa et al., 1994). Sprouting and neosynapse formation also occur in the CA1 pyramidal neurons, in which it has been shown that newly formed synapses produce an enhanced frequency of glutamatergic spontaneous synaptic currents (Esclapez et al., 1999) and the formation of novel aberrant kainatergic synapses on targets of mossy fibers (Epsztein et al., 2005). SE is also associated with dendritic loss of type $\mathrm{A} \mathrm{K}^{+}$channels in CA1 (Bernard et al., 2004), which results in heightened excitability. In addition, inhibitory input onto CA1 is perturbed after SE, with impaired dendritic inhibition and enhanced somatic inhibition (Cossart et al., 2001). Because the interplay between distal excitatory and proximal inhibitory oscillations is likely responsible for phase precession (Magee, 2001), it is likely that these changes are involved in our results.

Pathological changes can also be seen in other brain regions than the hippocampus, including amygdala, neocortex, substantia nigra, thalamus, piriform and olfactory cortex (Meldrum et al., 1974; Turski et al., 1987). Although we cannot exclude an involvement of these structures in altered spatial performance, the hippocampus is the most prominently affected structure in terms of cell loss and synaptic reorganization after SE.

In addition to causing hippocampal damage, lithiumpilocarpine SE can result in cell loss in the entorhinal cortex (EC). EC is a key input and output structure of the hippocampus, playing a critical role in sensory processing, memory, and learning (Parron et al., 2006), as well as in mechanisms of epileptic seizures. SE cell loss is observed principally in layer III of the medial EC (Du et al., 1995), layer that projects primarily to CA1 and the subiculum. In addition, in SE rats, layer II stellate cells (the major excitatory EC input to dentate gyrus) are hyperexcitable and generate a spontaneous, hypersynchronous input to the dentate gyrus (Kobayashi et al., 2003). It is important to note that cells in the dorsolateral medial entorhinal cortex show regular, equally distant grid-like patterns of firing across the environment (Hafting et al., 2005). This signal is believed to provide a metric frame in which the animal can update its location on the basis of path integration and to be at the origin of place cell signal. Interestingly, cells from layers II and V in this region, show phase precession patterns (Hafting et al., 2007). It is quite possible that after SE, entorhinal cells would also have abnormal phase precession resulting, downstream, in disturbances in CA1.

As has been demonstrated previously, MTLE caused by SE results in long-term deficits in learning, memory, and behavior in adult rats as well as in humans (Hermann et al., 2007). Although it is difficult to extrapolate data from rodents to humans, the pathological sequelae and cognitive abnormalities of MTLE in humans and rats are remarkably similar (Nadler, 1981; Ben-Ari, 1985). As in our rat model, MTLE is often precipitated by SE (Cossart et al., 2001). Although cognitive impairment may be progressive in some patients with MTLE that have poorly controlled epilepsy (Hermann et al., 2006), much of the cognitive impairment is a result of the initial insult (Elger et al., 2004; Helmstaedter and Kockelmann, 2006). Similar to the impairment found in the rats in spatial memory in the water maze, humans with medial temporal lobe epilepsy demonstrate impairment in navigation in a virtual reality maze (Weniger and Irle, 2006). Likewise, patients undergoing hippocampal resections for epilepsy are impaired in a virtual Morris water maze task (Astur et al., 2002).

In summary, our study shows that phase precession and compression of temporal sequences can be altered in an animal model of epilepsy. Our results demonstrate the importance of temporal encoding and oscillations in normal and pathological cognitive functions. Finally, the implications of disease-related impairment of temporal coding may go far beyond memory processes.

\section{References}

Agmon-Snir H, Carr CE, Rinzel J (1998) The role of dendrites in auditory coincidence detection. Nature 393:268-272.

Astur RS, Taylor LB, Mamelak AN, Philpott L, Sutherland RJ (2002) Humans with hippocampus damage display severe spatial memory impairments in a virtual Morris water task. Behav Brain Res 132:77-84.

Bailey NTJ (1995) Statistical methods in biology. Cambridge, UK: Cambridge UP.

Ben-Ari Y (1985) Limbic seizure and brain damage produced by kainic acid: mechanisms and relevance to human temporal lobe epilepsy. Neuroscience 14:375-403.

Bernard C, Anderson A, Becker A, Poolos NP, Beck H, Johnston D (2004) Acquired dendritic channelopathy in temporal lobe epilepsy. Science 305:532-535.

Burgess N, Barry C, O'Keefe J (2007) An oscillatory interference model of grid cell firing. Hippocampus 17:801-812. 
Buzsaki G (2007) The structure of consciousness. Nature 446:267.

Buzsaki G, Ponomareff GL, Bayardo F, Ruiz R, Gage FH (1989) Neuronal activity in the subcortically denervated hippocampus: a chronic model for epilepsy. Neuroscience 28:527-538.

Cossart R, Dinocourt C, Hirsch JC, Merchan-Perez A, De Felipe J, Ben-Ari Y, Esclapez M, Bernard C (2001) Dendritic but not somatic GABAergic inhibition is decreased in experimental epilepsy. Nat Neurosci 4:52-62.

Dan Y, Poo MM (2006) Spike timing-dependent plasticity: from synapse to perception. Physiol Rev 86:1033-1048.

Dragoi G, Buzsaki G (2006) Temporal encoding of place sequences by hippocampal cell assemblies. Neuron 50:145-157.

Du F, Eid T, Lothman EW, Kohler C, Schwarcz R (1995) Preferential neuronal loss in layer III of the medial entorhinal cortex in rat models of temporal lobe epilepsy. J Neurosci 15:6301-6313.

Elger CE, Helmstaedter C, Kurthen M (2004) Chronic epilepsy and cognition. Lancet Neurol 3:663-672.

Epsztein J, Represa A, Jorquera I, Ben-Ari Y, Crepel V (2005) Recurrent mossy fibers establish aberrant kainate receptor-operated synapses on granule cells from epileptic rats. J Neurosci 25:8229-8239.

Esclapez M, Hirsch JC, Ben-Ari Y, Bernard C (1999) Newly formed excitatory pathways provide a substrate for hyperexcitability in experimental temporal lobe epilepsy. J Comp Neurol 408:449-460.

Fenton AA, Csizmadia G, Muller RU (2000) Conjoint control of hippocampal place cell firing by two visual stimuli. II. A vector-field theory that predicts modifications of the representation of the environment. J Gen Physiol 116:211-221.

Fisher NI (1993) Statistical analysis of circular data. Cambridge, UK: Cambridge UP.

Geisler C, Robbe D, Zugaro M, Sirota A, Buzsaki G (2007) Hippocampal place cell assemblies are speed-controlled oscillators. Proc Natl Acad Sci USA 104:8149-8154.

Hafting T, Fyhn M, Molden S, Moser MB, Moser EI (2005) Microstructure of a spatial map in the entorhinal cortex. Nature 436:801-806.

Hafting T, Fyhn M, Molden S, Moser MB, Moser EI (2007) Phase precession and experience-dependent backward shift of entorhinal grid fields. Soc Neurosci Abstr 33:93.6.

Helmstaedter C (2002) Effects of chronic epilepsy on declarative memory systems. Prog Brain Res 135:439-453.

Helmstaedter C, Kockelmann E (2006) Cognitive outcomes in patients with chronic temporal lobe epilepsy. Epilepsia 47 [Suppl 2]:96-98.

Hermann B, Seidenberg M, Lee EJ, Chan F, Rutecki P (2007) Cognitive phenotypes in temporal lobe epilepsy. J Int Neuropsychol Soc 13:12-20.

Hermann BP, Seidenberg M, Schoenfeld J, Davies K (1997) Neuropsychological characteristics of the syndrome of mesial temporal lobe epilepsy. Arch Neurol 54:369-376.

Hermann BP, Seidenberg M, Dow C, Jones J, Rutecki P, Bhattacharya A, Bell B (2006) Cognitive prognosis in chronic temporal lobe epilepsy. Ann Neurol 60:80-87.

Holmes GL (2005) Effects of seizures on brain development: lessons from the laboratory. Pediatr Neurol 33:1-11.

Holmes GL, Gairsa JL, Chevassus-Au-Louis N, Ben-Ari Y (1998) Consequences of neonatal seizures in the rat: morphological and behavioral effects. Ann Neurol 44:845-857.

Holmes GL, Sarkisian M, Ben-Ari Y, Chevassus-Au-Louis N (1999) Mossy fiber sprouting after recurrent seizures during early development in rats. J Comp Neurol 404:537-553.

Huxter J, Burgess N, O’Keefe J (2003) Independent rate and temporal coding in hippocampal pyramidal cells. Nature 425:828-832.

Johnston D, Christie BR, Frick A, Gray R, Hoffman DA, Schexnayder LK, Watanabe S, Yuan LL (2003) Active dendrites, potassium channels and synaptic plasticity. Philos Trans R Soc Lond B Biol Sci 358:667-674.

Kobayashi M, Wen X, Buckmaster PS (2003) Reduced inhibition and increased output of layer II neurons in the medial entorhinal cortex in a model of temporal lobe epilepsy. J Neurosci 23:8471-8479.

Lenck-Santini PP, Muller RU, Save E, Poucet B (2002) Relationships be- tween place cell firing fields and navigational decisions by rats. J Neurosci 22:9035-9047.

Liu X, Muller RU, Huang LT, Kubie JL, Rotenberg A, Rivard B, Cilio MR, Holmes GL (2003) Seizure-induced changes in place cell physiology: relationship to spatial memory. J Neurosci 23:11505-11515.

Magee JC (2001) Dendritic mechanisms of phase precession in hippocampal CAl pyramidal neurons. J Neurophysiol 86:528-532.

Mardia KV, Jupp PE (2000) Directional statistics. New York: Wiley.

Maurer AP, McNaughton BL (2007) Network and intrinsic cellular mechanisms underlying theta phase precession of hippocampal neurons. Trends Neurosci 30:325-333.

McNaughton BL, Barnes CA, O’Keefe J (1983) The contributions of position, direction, and velocity to single unit activity in the hippocampus of freely-moving rats. Exp Brain Res 52:41-49.

Meldrum BS, Horton RW, Brierley JB (1974) Epileptic brain damage in adolescent baboons following seizures induced by allylgycine. Brain 97:407-418.

Mikati MA, Holmes GL, Chronopoulos A, Hyde P, Thurber S, Gatt A, Liu Z, Werner S, Stafstrom CE (1994) Phenobarbital modifies seizure-related brain injury in the developing brain. Ann Neurol 36:425-433.

Muller RU, Kubie JL (1987) The effects of changes in the environment on the spatial firing of hippocampal complex-spike cells. J Neurosci 7:1951-1968.

Nadler JV (1981) Minireview. Kainic acid as a tool for the study of temporal lobe epilepsy. Life Sci 29:2031-2042.

O'Keefe J (1976) Place units in the hippocampus of the freely moving rat. Exp Neurol 51:78-109.

O'Keefe J, Dostrovsky J (1971) The hippocampus as a spatial map. Preliminary evidence from unit activity in the freely-moving rat. Brain Res 34:171-175.

O'Keefe J, Recce ML (1993) Phase relationship between hippocampal place units and the EEG theta rhythm. Hippocampus 3:317-330.

Parron C, Poucet B, Save E (2006) Cooperation between the hippocampus and the entorhinal cortex in spatial memory: a disconnection study. Behav Brain Res 170:99-109.

Paxinos G, Watson C (1998) The rat brain in stereotaxic coordinates. San Diego: Academic.

Represa A, Niquet J, Pollard H, Khrestchatisky M, Ben-Ari Y (1994) From seizures to neo-synaptogenesis: intrinsic and extrinsic determinants of mossy fiber sprouting in the adult hippocampus. Hippocampus $4: 270-274$

Rutten A, van Albada M, Silveira DC, Cha BH, Liu X, Hu YN, Cilio MR, Holmes GL (2002) Memory impairment following status epilepticus in immature rats: time-course and environmental effects. Eur J Neurosci 16:501-513.

Schmid R, Tandon P, Stafstrom CE, Holmes GL (1999) Effects of neonatal seizures on subsequent seizure-induced brain injury. Neurology 53:1754-1761.

Schmitzer-Torbert N, Jackson J, Henze D, Harris K, Redish AD (2005) Quantitative measures of cluster quality for use in extracellular recordings. Neuroscience 131:1-11.

Skaggs WE, McNaughton BL, Wilson MA, Barnes CA (1996) Theta phase precession in hippocampal neuronal populations and the compression of temporal sequences. Hippocampus 6:149-172.

Sutula T, He XX, Cavazos J, Scott G (1988) Synaptic reorganization in the hippocampus induced by abnormal functional activity. Science 239:1147-1150.

Turski L, Cavalheiro EA, Czuczwar SJ, Turski WA, Kleinrok Z (1987) The seizures induced by pilocarpine: behavioral, electroencephalographic and neuropathological studies in rodents. Pol J Pharmacol Pharm 39:545-555.

Vanderwolf CH (1969) Hippocampal electrical activity and voluntary movement in the rat. Electroencephalogr Clin Neurophysiol 26:407-418.

Weniger G, Irle E (2006) Posterior parahippocampal gyrus lesions in the human impair egocentric learning in a virtual environment. Eur J Neurosci 24:2406-2414. 